\title{
CSF Potential Biomarkers $A \beta 42$ and Tau: associations of Apo E Genotype
}

\author{
Ramesh Kandimalla", KD Gill', SK Prabhakar ${ }^{2}$ \\ From $1^{\text {st }}$ International Congress on Neurobiology and Clinical Psychopharmacology and European \\ Psychiatric Association Conference on Treatment Guidance \\ Thessaloniki, Greece. 19-22 November 2009
}

\section{Background}

The most promising strategy to detect AD in preclinical or presymptomatic stage need specific biomarkers. In this study we elucidated the relationship between Apo E genotype and CSF biomarkers $A \beta 42$ and Total tau in Alzheimer's Disease (AD) Patients, Non AD (NAD) patients, Neurological controls (NCs) and Healthy Controls (HCs).

\section{Materials and methods}

In this study we included $30 \mathrm{HC}, 30 \mathrm{AD}$ patients, 40 NAD, and 46 NC from Nehru Hospital, PGIMER, Chandigarh, India after obtaining informed consent from all the subjects. Apo E Genotyping was done according to the Wenham PR etal,1991. The levels of $A \beta 42$ and total tau were determined by ELISA kits Innogenetics, Belgium.

\section{Results}

Our data of CSF A $\beta 42$ and tau levels in conjunction with $\varepsilon 4$ allele had shown specificity and sensitivity of $100 \%$ and $42.8 \%$ respectively for the detection of AD. $A \beta 42$ and Apo E $\varepsilon 4$ combination had shown specificity $80.8 \%$ and sensitivity $72.1 \%$. The $\varepsilon 4$ allele distribution frequency was $40 \%$ and $2.5 \%$ in $\mathrm{AD}$ and NAD respectively, where as $\varepsilon 4 / 4$ genotype and $\varepsilon 3 / 4$ genotype distribution was $10 \%$ and $50 \%$ respectively. Our data has shown that $\varepsilon 4$ allele in combination with $A \beta 42$ to have better sensitivity and specificity in the diagnosis of $A D$. $\mathrm{AD}$ patients with at least one $\varepsilon 4$ allele had significantly lower CSF A $\beta 42$ levels than those without $\varepsilon 4$ allele $(\mathrm{P}<0.001)$. There was a positive correlation of $\mathrm{A} \beta 42$ with low MMSE scores.

\section{Conclusions}

Observation from our study suggest that decreased A $\beta 42$ and increased tau level in CSF along with Apo E $\varepsilon 4$ allele as risk factors for AD. Our study also shows $\varepsilon 4$ allele incidence to be a risk factor for AD.

\section{Acknowledgements \\ ICMR, New Delhi, India for funding this study and Senior Residents of department of neurology. Colleagues Nidhi, Deep raj and Aditya}

\section{Author details}

${ }^{1}$ Department of Biochemistry, PGIMER, Chandigarh, India. ${ }^{2}$ Department of Neurology, PGIMER, Chandigarh, India.

Published: 22 April 2010

\section{References}

1. Wenham PR, Price WH, Blandell G: Apolipoprotein E genotyping by onestage PCR. Lancet 1991, 337:1158-9.

2. Tapiola T, Pirttila T, Mehta PD, Alafuzofff I, Lehtovirta M, Soininen H: Relationship between apoE genotype and CSF beta-amyloid (1-42) and tau in patients with probable and definite Alzheimer's disease. Neurobiol Aging 2000, 2:735-40.

3. Riemenschneider M, Schmolke M, Lautenschlager N, Vanderstichele $H$, Vanmechelen E, Guder WG, et al: Association of CSF apolipoprotein E, Abeta42 and cognition in Alzheimer's disease. Neurobiol Aging 2002, 23:205-11.

4. Petersen RC, Smith GE, Ivnik RJ, Tangalos EG, Schaid DJ, Thibodeau SN, et al: Apolipoprotein E status as a predictor of the development of Alzheimer's disease in memory-impaired individuals. JAMA 1995, 273:1274-8.

doi:10.1186/1744-859X-9-S1-S104

Cite this article as: Kandimalla et al: CSF Potential Biomarkers A 42 and Tau: associations of Apo E Genotype. Annals of General Psychiatry 2010 9(Suppl 1):S104.

'Department of Biochemistry, PGIMER, Chandigarh, India 